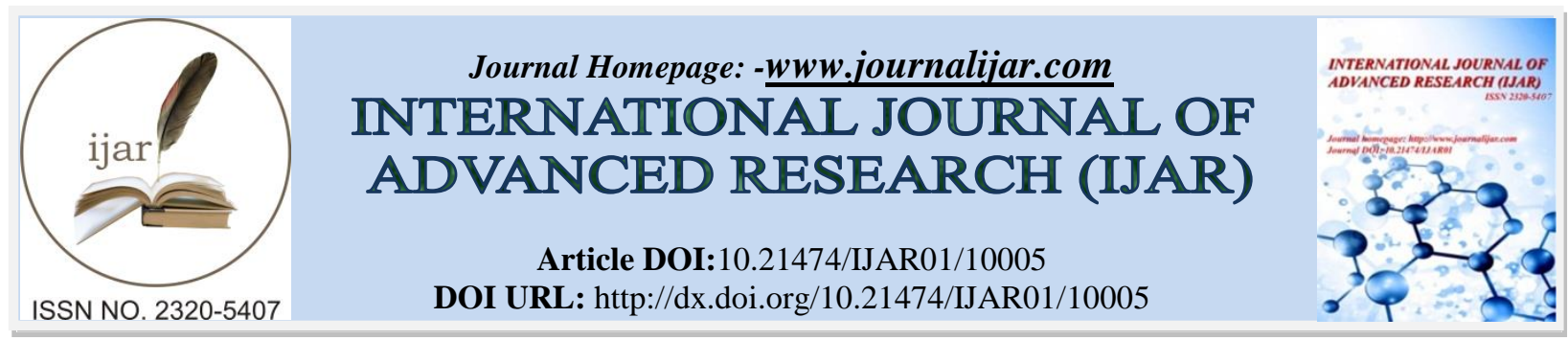

RESEARCH ARTICLE

\title{
PROTECTIVE ROLES OF VITAMIN E TOWARD FORMALDEHYDE INDUCE DAMAGE IN FEMALE ALBINO MICE.
}

\author{
Soad A. Treesh ${ }^{1}$, Medeha T. Elghedamsi ${ }^{2}$, Suhera M. Aburawi ${ }^{2}$, Habiba A. El Jaafari ${ }^{3}$, Marwa A. Shneba ${ }^{2}$, \\ Mawada M. Elfellan² and Naema Shibani' ${ }^{2}$. \\ 1. Department of Histology and Medical Genetics, Faculty of Medicine, University of Tripoli, LIBYA. \\ 2. Department of Pharmacology and Clinical Pharmocy, Faculty of Pharmacy, University of Tripoli, LIBYA. \\ 3. Zoology Department, Science Faculty - University of Tripoli, LIBYA.
}

\section{Manuscript Info}

..........................

Manuscript History

Received: 08 September 2019

Final Accepted: 10 October 2019

Published: November 2019

Key words:-

Infertility, Antioxidant, Vitamin E,

Formaldehyde.

\section{Abstract}

The etiology of female infertility can be broken down into ovulation disorders uterine abnormalities, tubal obstruction, and peritoneal factors, cervical factors are also thought to play a minor role. Vitamin E is a fat-soluble antioxidant that stops the production of Reactive oxygen species (ROS) formed when fat undergoes oxidation; it may prevent or delay the chronic diseases associated with free radicals .The present study was designed to investigate the protective roles of antioxidants as vitamin $\mathrm{E}$ toward formaldehyde induce damage in female reproductive system. Female mice ( $\mathrm{n}=50,25-40 \mathrm{gm})$ were mated, every five female mice with one male mouse for 6 days for breeding. On the sixth day, female mice were divided into five groups: group 1 (control) administered tween $80(5 \mathrm{ml} / \mathrm{kg})$ for 5 days, group 2 received formaldehyde $(30 \mathrm{mg} / \mathrm{kg}$ ) for 5 days, group 3 received vitamin $\mathrm{E}$ $(100 \mathrm{mg} / \mathrm{kg})$ for 5 days, group 4 administered formaldehyde and vitamin $\mathrm{E}$ (prophylactic) for 5 days, group 5 received formaldehyde for 5 days followed by vitamin $\mathrm{E}$ for another 5 days (curative). At the end of 21 days, animals were sacrificed; ovaries and uterus were removed and fixed in $10 \%$ formalin solution for routine histological techniques. Intraperitoneal administration was adopted in this study.

Results: it was found that formaldehyde induced reproductive and developmental toxicities result in precipitous pathologies affecting female reproduction; Vitamin $\mathrm{E}$ is well accepted as nature's most effective lipid-soluble, chain-breaking antioxidant, protecting cell membranes from free- radical mediated per oxidative damage. It can be concluded that formaldehyde causes toxicity in female reproductive system. Vitamin E repair and treat formaldehyde toxicity. The improvement induced by vitamin $\mathrm{E}$ was more significant in treated group compared with prophylactic group.

Copy Right, IJAR, 2019,. All rights reserved.

Corresponding Author:-Soad A. Treesh.

Address:-Department of Histology and Medical Genetics, Faculty of Medicine, University of Tripoli, Libya. 


\section{Introduction:-}

The etiology of female infertility can be broken down into ovulation disorders uterine abnormalities, tubal obstruction, and peritoneal factors, cervical factors are also thought to play a minor role, although they are rarely the sole caudw [1].

The production of Reactive oxygen species (ROS) is stoped by Vitamin E (Vit.E), which is a fat-soluble antioxidant; it may prevent or delay the chronic diseases associated with free radicals [2]. There are eight chemical forms of vitamin E (alpha, beta, gamma, and delta-tocopherol and alpha, beta, gamma, and delta tocotrienol) [2].

In addition to its activities as an antioxidant, vitamin $\mathrm{E}$ is involved in immune function and, cell signaling, regulation of gene expression, and other metabolic processes [2].

The adverse effects from consuming vitamin $\mathrm{E}$ in food and the potential adverse effects of high-dose vitamin $\mathrm{E}$ supplements are unclear $[3, \mathbf{4 , 5}]$.

Women use vitamin $\mathrm{E}$ for preventing complications in late pregnancy due to high blood pressure (pre- eclampsia), premenstrual syndrome (PMS) [6], painful periods, menopausal syndrome, hot flashes associated with breast cancer [7].

Cells have developed a wide range of antioxidants systems to limit production of ROS, inactivate them and repair cell damage $[8,9,10,11]$. ROS influences the entire reproductive span of women's life and even [12] thereafter (i.e. menopause). It has been suggested that ROS modulate the age-related decline in fertility [12].

The effects of Formaldehyde (FD) on ROS are seen in in-vitro studies or after injection [13]. Most of the epidemiology, studies examined spontaneous abortion and showed some evidence of increased risk [13]. Recently, it was found that formaldehyde pass the placenta [14].

Potential mechanisms underlying formaldehyde-induced reproductive and developmentaltoxicities, including chromosome and DNA damage (genotoxicity), oxidative stress, altered level and/or function of enzymes, hormones and proteins, apoptosis, toxicogenomic and epigenomic effects (such as DNA methylation) [15].

In animals $\alpha$-tocopherol (the most active form of vitamin E) is membrane bound which was suggested to have a dual role where the phenolic nucleusacts as an antioxidant on the surface of the membrane while the side chain stabilizes the membrane. Thus, the molecular mechanism of vitamin $\mathrm{E}$ is mediated by the antioxidant function or its membrane stabilizing effect [16].

\section{Aim:-}

The present study was designed to investigate the protective roles of antioxidants as vitamin E toward formaldehyde induces damage in female reproductive system.

\section{Materials and methods:-}

\section{Materials:}

Vitamin E supplement was obtained from genesisvit natural USA; Formaldehyde, $\mathrm{NaCl}$ and Eosin $\mathrm{Y}$ were purchased from Red El-De Haen AG Seelze-Hannover - Germany.

\section{Methods:}

Female mice ( $\mathrm{n}=50,25-40 \mathrm{gm})$ were mated, every five female mice with one male mouse for 6 days for breeding. On the sixth day female mice were divided into 5 groups: group 1 (control) administered tween $80(5 \mathrm{ml} / \mathrm{kg}$ ) for 5 days, group 2 received formaldehyde $(30 \mathrm{mg} / \mathrm{kg}$ ) for 5 days, group 3 received vitamin E $(100 \mathrm{mg} / \mathrm{kg})$ for 5 days, group 4 administered formaldehyde and vitamin E (prophylactic) for 5 days, group 5 received formaldehyde for 5 days followed by vitamin $\mathrm{E}$ for another 5 days (curative). At the end of 21 days, animals were sacrificed; ovaries and uterus were removed and fixed in $10 \%$ formalin solution for routine histological techniques. Intraperitoneal administration was adopted in this study. 


\section{Histological study:}

At the end of the administration, mice were sacrificed, uterus and ovary of treated mice were removed and then were fixed in formalin for 24 hours. The specimens were washed twice with $70 \%$ alcohol. The fixed tissues were dehydrated in an ascending series of alcohol ranging from $70 \%$ to $100 \%$ (absolute). The dehydrated tissues were cleared in xylene (twice), infiltrated and then were embedded in paraffin wax. The uterus or ovary were sectioned on a rotary microtome, sections were $5 \mu \mathrm{m}$ in thickness. The prepared sections were stained by routine methods using Hematoxylin-eosin method [17]. The stained sections were examined under the microscope and the different cell types were carefully studied and photographed. Uterus and ovary sections from each study group were evaluated for structural changes, blind. Light microscopy (Leica, Germany) was used for the evaluations.

\section{Results:- \\ Control group \\ Ovary Control}

The control group showed the known histological structure of the ovary; simple cuboidal epithelium covers the ovary, growing follicles primary, secondary, and corpus luteum in ovarian cortex (Fig.1 a, b).

\section{Uterus Control}

The uterus of control mice's showed ; a simple columnar epithelium(Fig. 1 c ,d), smooth muscle layers; inner longitudinal, middle circular, and outer longitudinal of myometrium (Fig. 1, d).

\section{Formaldehyde Exposure group}

\section{Formaldehyde Exposure ovaries:}

Sections of the ovary mice injected with FD showed: increase of the thickness of tunica albuginea and increase in interstitial cells around the growing follicles (Fig. 2 a, b).

The growing follicles increased in number while the primordial follicles were few (Fig. 2 a). Corpora lutea ,atretic follicles, numerous dilated blood vessels found in interstitial tissue (Fig. 2 c) lysis of the primary oocyte and acidophilic material filling the cavity of follicular antrum (Fig. 2 d). Pyknosis nuclei shown in surrounding granulosa cells (Fig. 2 e, f). Normal growing follicle was also seen (Fig. 2, a). Other follicles were undergone atresia , engorged blood vessels occupying the ovarian stroma with the vacuolation of the interstitial cells (Fig. $2 \mathrm{c}$ ).

\section{Formaldehyde Exposure Uterus:}

Compared to the uteri of control group, uterus of mice treated with FD characterized by decreased prominence of endometrial glands, less and few uterine glands. Degeneration of luminal epithelium and decrease in its thickness , cellular vacuolar degeneration (Fig.3 a, b).

Most nuclei of glandular and luminal epithelium have heterochromatin. Note congested blood vessel (Fig. 3 b). Distortion and degeneration of luminal epithelium . Necrosis of the endometrial glands. Stromal mitotic figures (Fig.3 c, d). Proliferative endometrium with a small focus to the gland, some cells within the gland (abortive cells), Vaculation of endometrial epithelial cells, endometrial glands showed some damage and sloughing off of the lining endometrial epithelial cells (Fig. 3, b).

\section{Vitamin E group}

\section{Vit. E exposure ovaries:}

\section{Sections of the ovary mice injected with Vit. E showed:}

Normal appearance of the ovary (Fig. 4 a, b). Increasing number of CL and few primordial follicles (Fig. 4 a, b), however numerous blood vessels in interstitial tissue among atretic follicles \& corpora lutea were observed; there is an absence of growing follicle or atretic follicle (Fig. 4, b).

\section{Vit. E exposure uterus:}

Sections of the uterus mice injected with Vit. E showed: Normal appearance of epithelial and stroma of endometrium but with marked increase number of uterine glands (Fig. 4 c, d). 


\section{Vit. E (Prophylaxis) exposure ovaries:}

The ovaries showed presence of little primordial follicle but increasing of normal growing follicles, some cystic or atretic follicles were appear, tunica albuginea showed slightly thickness than control group. The corpora lutea were observed (Fig.5 a, b).

\section{Vit. E (Prophylaxis) exposure uterus:}

This group showing pseudostratification and mitosis of glandular epithelium. Several mitotic figures are seen in the glands with normal lining epithelium of endometrium, the myometrium is intact (Fig. 5 c, d).

\section{Vit. E (Treatment) exposure ovaries:}

The ovaries showed presence of normal growing follicles, the tunica albuginea with normal thickness, proliferation of interstitial cells, and some congested blood vessels in medulla.

The corpora lutea were observed (Fig. 6 a, b).

\section{Vit. E (Treatment) exposure uterus:}

This group showing normal appearance of luminal epithelium, thickening of endometrium with marked narrowing of the lumen. Nearly normal appearance of glandular and its luminal epithelium (Fig. 6 c, d).

\section{Discussion:-}

Formaldehyde can react with different macromolecules such as proteins and nucleic acid, or with low molecular weight substances such as amino acids $[18,19]$. Furthermore, Formaldehyde is a highly water soluble compound which can rapidly diffuse into many tissues [20]. Potential mechanisms underlying formaldehyde-induced reproductive and developmental toxicities, including chromosome and DNA damage (genotoxicity), oxidative stress, altered level and/or function of enzymes, hormones and proteins, apoptosis, toxicogenomic and epigenomic effects (such as DNA methylation) [15].

The physiological functions of the reproductive tract can be affected by Reactive oxygen species (ROS ) [21]. Where it produced within the follicle especially during the ovulatory process, an excessive amount of ROS causes oxidative stress and may damage oocyte and granulosa cells. Accumulating data have shown that ROS accelerate oocyte aging and deteriorate oocyte quality $[\mathbf{2 2}, \mathbf{2 3}]$.

The follicles have antioxidant defense systems, such as superoxide dismutase (SOD) or glutathione (GSH). The balance between ROS and antioxidants within the follicle seems to be critical to the function of oocyte and granulosa cells [24].

During follicular rupture, the ROS produced. Luteinizing hormone (LH) surge induces dissolution of the basement membrane between the granulosa and theca interna layers and an expansion of the theca capillaries into the avascular granulosa cell layer to form a dense network of capillaries $[25, \mathbf{2 6}]$.

However, excess ROS can also be responsible for oxidative stress; they can damage molecules and structures of oocyte and granulosa cells within the follicle. ROS must be continuously deactivated to keep only the small amount necessary to maintain normal cell function. Follicular components, cumulus cells and the follicular fluid may protect the oocytes from the damaging effects of ROS $[27,28,29]$.

ROS induce lipid peroxidation of membranes and DNA damage in the oocyte and are expected to cause harmful effects in cell division, metabolite transport, and mitochondrial function [30].

The formaldehyde can interact with molecules on cell membranes (e.g., proteins and DNA) and disrupt cellular functions. High concentrations cause precipitation of proteins, which results in cell death. Once absorbed, formaldehyde is oxidized to formic acid and $\mathrm{Co} 2$, which may cause acid base imbalance and a number of other systemic defects [31].

The imbalance due to increased ROS or decreased antioxidants causes the oxidative stress, and may lead to an ovulation, dysfunctional oocytes, fertilization failure, implantation failure, or miscarriage [32]. 
Vitamin E is well accepted as nature's most effective lipid-soluble, chain-breaking antioxidant, protecting cell membranes from free-radical mediated peroxidative damage [33], when mice were given antioxidant supplements (vitamins $\mathrm{C}$ and $\mathrm{E}$ ), an increased number of normal MII oocytes and decreased percentage of apoptotic oocytes were observed in comparison with the control group [34].

\section{Conclusion:-}

Based on the finding of this study, it can be concluded that formaldehyde causes toxicity in female reproductive system. Vitamin E repair and treat FA toxicity. The improvement induced by vitamin E was more significant in treated group compared with prophylactic group.

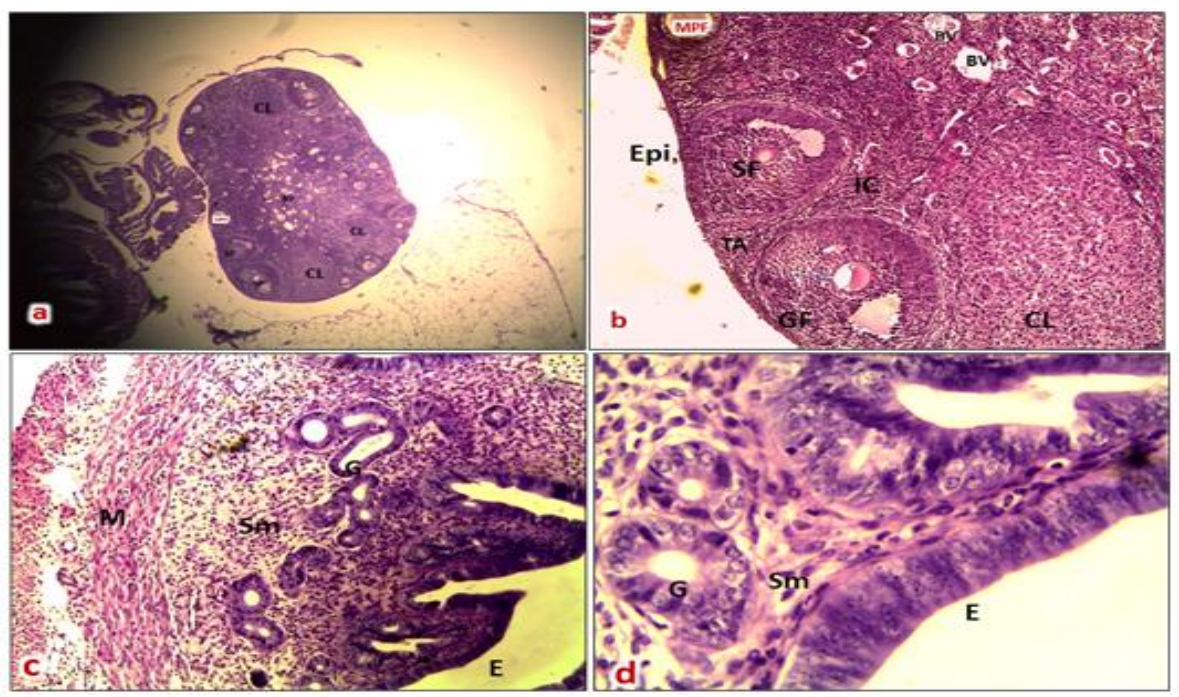

Figure1:- Photomicrographs of control mice ovary and uterus showing;

a. Overview of control ovary showing primordial follicle (P), corpus luteum (CL) (H\&E, 250x).

b. A single layer of cuboidal surface epithelium (E), underneath it an aggregates of interstitial cells (IC) are found. Note the presence of tertiary follicle (GF), well defined corona radiate (arrow) (H\&E, 100x).

c. Normal histological features of endometrium containing lining epithelium of simple columnar (E), uterine glands $(\mathrm{G})$ in lamina properia (LP) and Myometrium (M) (H\&E, 100x).

d. Endometrium contains smooth muscle (Sm) in interstitium and uterine glands (G) (H\&E, 400x).
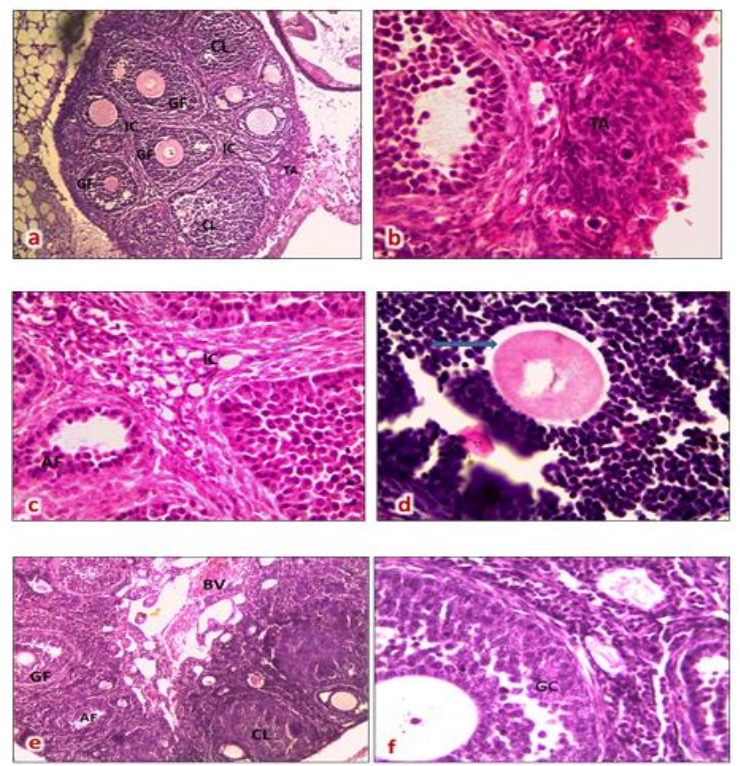

Figure 2:-Photomicrographs of FD treated mice ovaries showing; 
a. Denoting proliferation of the interstitial cells among growing follicles(IC) (H\&E, 100x).

b. A thickening of Tuica albuginea (TA) (H\&E, 100x).

c. Numerous blood vessels in interstitial tissue (IC) among atretic follicles (AF) (H\&E, 400x).

d. Lysis of the primary oocyte and appearance of acidophilic material filling the cavity of follicular antrum (H\&E, 400x).

e. Pyknosis of nuclei and cytoplasm of granulosa cells (H\&E, 400x).

f. Pyknosis of nuclei and cytoplasm of granulosa cells (H\&E, 400x).

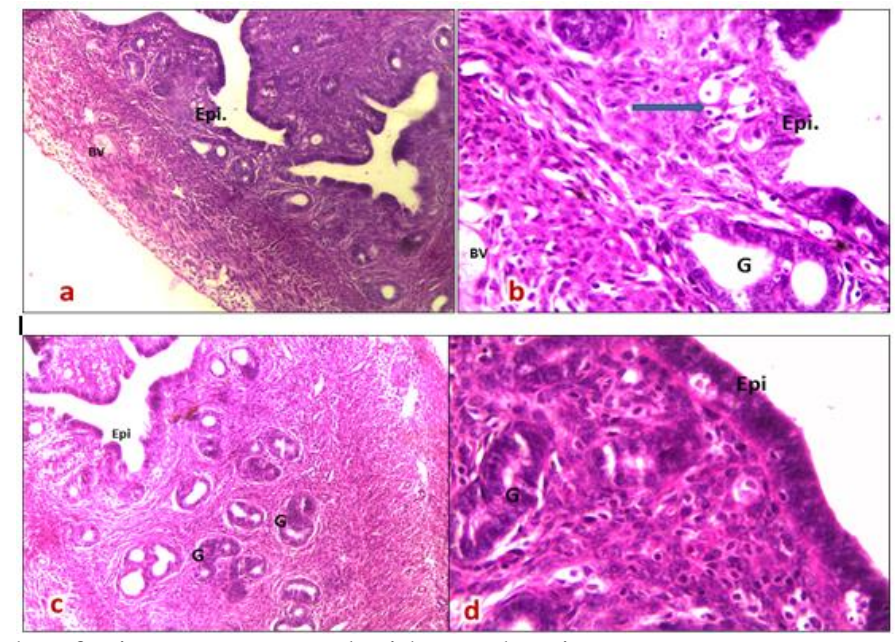

Figure 3:-Photomicrographs of mice uterus treated with FD showing;

a. Endometrium showing decreased prominence of endometrial glands, congested blood vessels (BV) (H\&E, 100x)

b. Vacuolar degeneration in endometrial epithelial cells (arrow), damage of endometrial glands $(\mathrm{G})$, congested blood vessels (BV) (H\&E, 400x).

c. Sloughing off of the lining endometrial epithelial (Epi.) (H\&E, 100x).

d. Higher magnification of previous figure showing degeneration of glandular epithelium $(\mathrm{G})$ \& vacuolar degeneration in endometrial epithelial cells (Epi.) (H\&E, 400x).
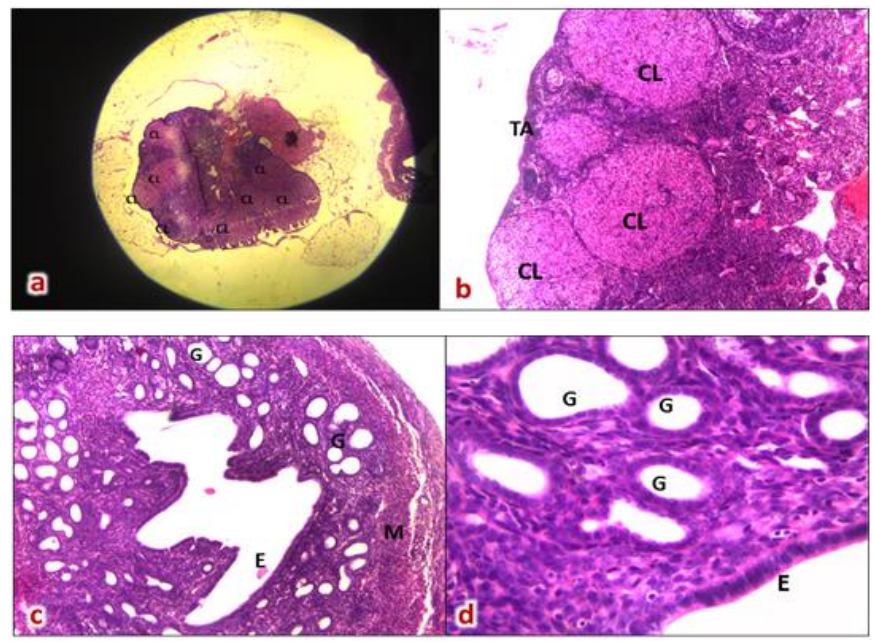

Figure 4:-Photomicrographs of mice ovary \& uterus treated with Vit.E showing;

a. A photomicrograph of mice ovary showing corpora lutei (CL) (H\&E, 250x).

b. Normal tunica albuginea (TA), underneath it numerous number of corpus letium (CL) (H\&E, 100x).

c. A photomicrograph of mice uterus showing normal histological features of endometrium containing lining epithelium of simple columnar (E), massive increase of uterine glands (G) (H\&E, 100x).

d. Higher magnification of previous figure showing many normal uterine glands (G) \& normal epithelium (E) (H\&E, 400x). 

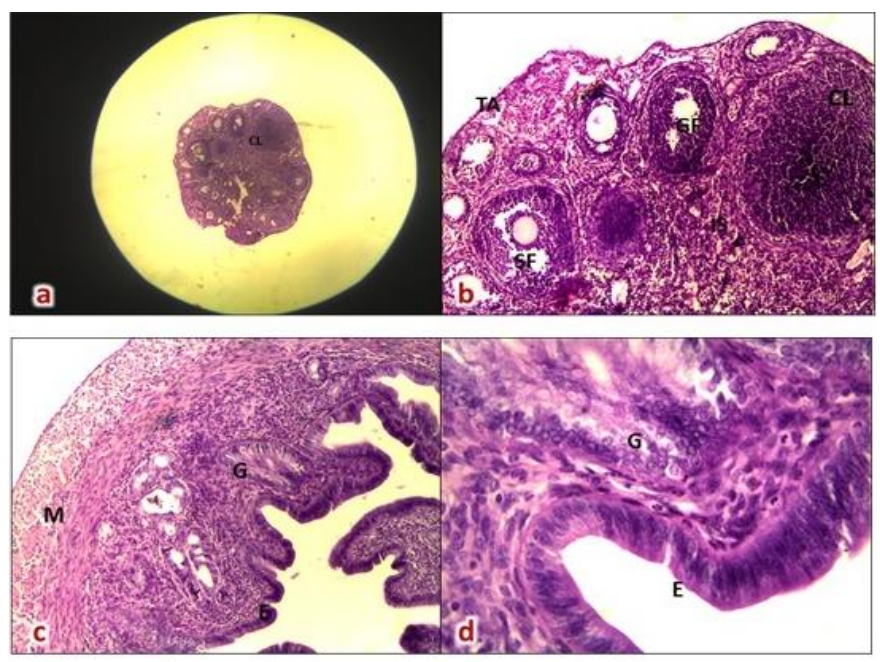

Figure 5:-Photomicrographs of mice ovary \& uterus treated with FD \& Vit.E (prophylaxis) showing;

a. A photomicrograph of mice ovary (H\&E, 250x).

b. Normal tunica albuginea (TA), underneath it amultilaminar primary follicles (GF) and (SF), and interstitial cells (IS) in between them. Large corpous letium (CL) (H\&E, 100x).

c. Normal histological features of endometrium containing lining epithelium of simple columnar (E), normal appearance of myometrium (M) (H\&E, 100x).

d. Higher magnification of previous figure showing proliferation of glandular epithelium (G) \& normal epithelium (E) $(H \& E, 400 x)$.
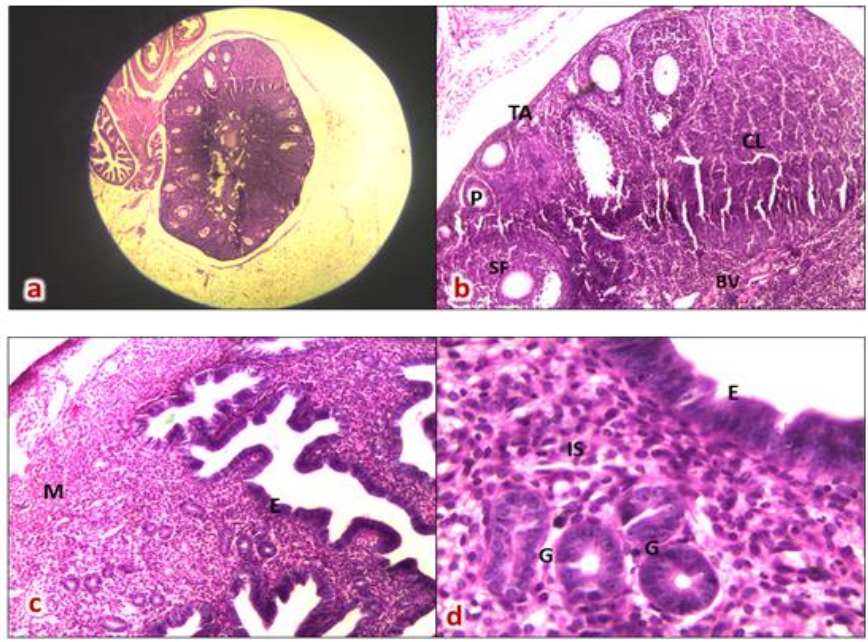

Figure 6:-Photomicrographs of mice ovary \& uterus treated with FD \& then with Vit.E (treatment) showing;

a. Ovary appears nearly normal (H\&E, 250x).

b. Presence of primordial follicle (P), secondry folloicle (SF), congested blood vessels (BV) (H\&E, 100x).

c. Normal histological features of endometrium with many projections (E), normal appearance of myometrium (M) (H\&E, 100x).

d. Higher magnification of previous figure showing normal uterine gland $(\mathrm{G}) \&$ normal epithelium (E) (H\&E, 400x).

\section{Reference:-}

1. Pfeifer S, Goldberg J, Lobo R, McClure R, Thomas M, Widra E, Licht M, Collins J, Cedars M, Racowsky C, Davis O, Gracia C, Catherino W, Thornton K, Rebar R, La Barbera (2012). A practice committee of American society for reproductive medicine . Diagnostic evaluation of the infertile female: a committee opinion. Fertile steril, 98(2) 302_307. 
2. Traber MG. Vitamin E. In: Shils ME, Shike M, Ross AC, Caballero B, Cousins R, eds (2006). Modern Nutrition in Health and Disease. 10th ed. Baltimore, MD: Lippincott Williams \& Wilkins,; 396-411.

3. Institute of Medicine. Food and Nutrition Board. Dietary Reference Intakes: Vitamin C, Vitamin E, Selenium, and Carotenoids ${ }^{*}$. Washington, DC: National Academy Press, (2000).

4. Miller ER 3rd1, Pastor-Barriuso R, Dalal D, Riemersma RA, Appel LJ, Guallar E. (2005).Comments and responses: high dosage vit. E supplementation and all-cause mortality. Ann Intern Med;143:150-7.

5. Various authors.(2007) Letters: antioxidant supplements and mortality. JAMA;298:400-3.

6. London RS , Murphy L, Kitlowski KE , Reynolds MA.(1987) . Efficacy of alpha-tocopherol in the treatment of the premenstrual syndrome. The Journal of Reproductive Medicine .[32(6):400-404].

7. Barton DL, Loprinzi CL, Quella SK, Sloan JA, Veeder MH, Egner JR, et al. (1998). Prospective evaluation of vitamin $\mathrm{E}$ for hot flashes in breast cancer survivors. J Clin Oncol;16:495-500.

8. Zhai H, Behnam S, Villarama CD, Arens-Corell M, Choi MJ, Maibach HI (2005). Evaluation of the antioxidant capacity and preventive effects of a topical emulsion and its vehicle control on the skin response to UV exposure. Skin Pharmacol Physiol.18:288-93. Doi: 10.1159/000088014.

9. Hadshiew IM, Treder-Conrad C, Bulow R, Klettle E, Mann T, Stab F, et al.(2004). Polymorphous light eruption (PLE) and a new potent antioxidant and UVA- protective formulation as prophylaxis. Photodermatol Photoimmunol Photomed; 20: 200-4.

10. Brown RK, Kelly FJ.(1994). Role of free radicals in the pathogenesis of cystic fibrosis. Thorax;49:738-42.

11. Omu AE, Al-Azemi MK, Kehinde EO, Anim JT, Oriowo MA et al.(2008).Indications of the mechanismsinvolvedin improved sperm parameters by zinc therapy.MedPrincPract; 17: 108-16.

12. JaliliT, KhakiA, GhanbariZ, ImaniA ,HatefiF.(2014). A Study of the Therapeutic Effects of Vitamin E on Testicular Tissue Damage Caused by Fluoxetine. Crescent Journal of Medical and Biological sceinces. Vol.1,No.2, spring 2014, 37-41.

13. Szczepanska M, Kozlik J, Skrzypczak J, Mikolajczyk M. (2003). Oxidative stress may be a piece in the endometriosis puzzle. Fertil Steril.79:1288-1293. Doi: 10.1016/S0015-0282(03)00266-8.

14. Van Langendonckt A, Casanas-Roux F, Donnez J. (2002). Oxidative stress and peritoneal endometriosis. Fertil Steril.77:861-870. Doi: 10.1016/S0015-0282(02)02959-X.

15. Pierce JD, Cackler AB, Arnett MG. (2004). Why should you care about free radicals? US National Library of MedicineNational Institutes of Health.RN. 67:38-42. quiz 43.

16. Agarwal A, Allamaneni SS. (2004). Role of free radicals in female reproductive diseases and assisted reproduction. Reprod Biomed Online.9:338-347.

17. Bancroft JD, Gamble M. (2002). "Theory and practice of histological techniques", $5^{\text {th }}$ ed. Philadelphia: Churchill Livingstone; pp. 125-138.

18. Pekiner B D (2003). Vitamin E as an antioxidant. J. Fac. Pharm, Ankara 32 (4) 243-267.

19. Reuss G, Disteldorf W, Gamer A O, Hilt A.(2002)."Formaldehyde" in Ullmann's Encyclopedia of Industrial Chemistry, Wiley-VCH, Weinheim. doi:10.1002/14356007.a11_619.

20. International Agency for Research on Cancer (IARC): Some industrial chemicals and dyestuffs. IARC Monogr. Eval. Carcinog. Risk Chem. Hum., 29. (1982), 345-389.

21. Costa S, Carvalho S, Costa C, Coelho P, Silva S, Santos LS, Gaspar JF, Porto B, Laffon B, Teixeira JP.(2015). Increased levels of chromosomal aberrations and DNA damage in a group of workers exposed to formaldehyde.US National Library of MedicineNational Institutes of Health .30(4):463-73. Doi: 10.1093.

22. Duong A, Steinmaus C, McHale CM, Vaughan CP, Zhang L.(2011). Reproductive and developmental toxicity of formaldehyde.US National Library of MedicineNational Institutes of Health.728(3):118-38. doi: 10.1016.

23. Collins JJ1, Ness R, Tyl RW, Krivanek N, Esmen NA, Hall TA.(2011). A review of adverse pregnancy outcomes and formaldehyde exposure in human and animal studies.Regulatory Toxicology and Pharmacology .34(1):17-34.

24. Thrasher J.D., and Kilburn K.H. (2010). Embryo Toxicity and Teratogenicity of Formaldehyde. Archives of Environmental Health: An International Journal; 56(4): 300-311. DOI: 10.1080/00039890109604460.

25. Schmid O, Speit G.(2006). Genotoxic effects induced by formaldehyde in human blood and implications for the interpretation of biomonitoring studies.oxford journals. Pp. 69-74.

26. Zhang Y, Liu X, McHale C, Rui Li, Zhang L, Wu Y,Xin Ye, Yang X,and DingS.(2013). Bone Marrow Injury Induced via Oxidative Stress in Mice by Inhalation Exposure to Formaldehyde. US National Library of MedicineNational Institutes of Health.8(9): e74974.

27. Madu. E.P.(2015). Teratogenic and embryotoxic effects of orally administered cypermethrin in pregnant albino rats. Journal of Toxicology and Environmental Health Sciences.Vol.7(7):60-67. 
28. Cheng G, Shi Y, Sturla SJ, Jalas JR, McIntee EJ, Villalta PW, et al.(2003) . Reactions of formaldehyde plus acetaldehyde with deoxyguanosine and DNA: formation of cyclic deoxyguanosine adducts and formaldehyde cross-links. Chem Res Toxicol; 16: 145_52.

29. Metz B, Kersten GF, Hoogerhout P, Brugghe HF, Timmermans HA, de Jong A, et al.(2004). Identification of formaldehyde-induced modifications in proteins: reactions with model peptides. J Biol Chem. 279: 6235_43.

30. Gurel A, Coskun O, Armutcu F, Kanter M, Ozen OA. (2005). Vitamin E against oxidative damage caused by formaldehyde in frontal cortex and hippocampus: biochemical and histological studies. J Chem Neuroanat . 29: 173_8.

31. Sekhon, Gupta S,Kim Y and Agarwal A.(2010). Female Infertility and Antioxidants. Current Women's Health Reviews.6, 84-95.

32. Goud AP, Goud PT, Diamond MP, Gonik B, Abu-Soud HM. (2008). Reactive oxygen species and oocyte aging: role of superoxide, hydrogen peroxide, and hypochlorous acid.Free Radic Biol Med .44(7):1295-1304. $10.1016 / \mathrm{j}$.

33. Yang HW, Hwang KJ, Kwon HC, Kim HS, Choi KW, Oh KS.(1998). Detection of reactive oxygen species (ROS) and apoptosis in human fragmented embryos. Hum Reprod .13(4):998-1002. 10.1093/humrep/13.4.998

34. Guerin P, El Mouatassim S, Menezo Y. (2001). Oxidative stress and protection against reactive oxygen species in the pre-implantation embryo and its surroundings.Hum Reprod Update.7 (2):175-189. 